\title{
Light moves life
}

\section{Halina Rubinsztein-Dunlop}

Halina Rubinsztein-Dunlop, "Light moves life," Proc. SPIE 9721, Nanoscale Imaging, Sensing, and Actuation for Biomedical Applications XIII, 972102 (8 March 2017); doi: 10.1117/12.2225244

SPIE. Event: SPIE BiOS, 2016, San Francisco, California, United States 


\title{
Light Moves Life \\ (Conference Presentation) \\ Halina Rubinsztein-Dunlop, The Univ. of Queensland, Australia
}

\begin{abstract}
Light can be made to do the work. Imagine tweezers made out of light. Such optical tweezers can trap and move materials noninvasively at length scales ranging from tens of nanometers to tens of micrometers, and so have provided unprecedented access to physical, chemical and biological processes on a microscale. Since a light beam can carry angular momentum it is possible to use optical tweezers to exert torques to twist or rotate nano and microscopic objects. These optical rotors can be used to map the mechanical properties of cells. They can also be used in biotechnology and optomechanics.
\end{abstract}

View presentation recording on the SPIE Digital Library:

http://dx.doi.org/10.1117/12.2225244 